\title{
Reinforced MFC aerogel for heavy metal ions separation
}

\author{
Jinhua $\mathrm{Yan}^{1, \text { a }}$ \\ ${ }^{1}$ Guangdong Industry Technical College, Guangzhou, 510300, China \\ aemail:jhyan2013@163.com
}

Keywords: MFC aerogel; chitosan; absorbent; heavy metal ions

Abstract. Mirco-fibrillated cellulose (MFC) aerogel was reinforced by chitosan. The reinforced MFC aerogel was used as heavy metal ions absorbent. The results showed that the aerogel had good absorption capacity of over $200 \mathrm{mg} / \mathrm{g}$ for all 4 kinds of heavy metal ions, $\mathrm{Cd} 2+, \mathrm{Zn} 2+, \mathrm{Pb} 2+$ and $\mathrm{Cr} 6+$ in the initial concentration range of $50-1000 \mathrm{mg} / \mathrm{L}$. The aerogel had little effect on contact time, but showed dependence on ion initial concentration. The reinforced MFC aerogel is a novel and attractive absorbent for heavy metal ions separation.

\section{Introduction}

Micro-fibrillated cellulose (MFC) is isolated from natural cellulose fibers by basically mechanical action after enzyme or chemical pretreatment. MFC has been widely investigated recently due to its sustainable, renewable, and biocompatible nontoxic properties for relatively high physical-chemical stability materials [1-3]. These aerogels are based on the hydrogen bond formation between MFC [4]. Unfortunately, these hydrogen bonds can be easily destroyed by immersing the aerogels in water, which limited the application of the aerogels.

Chemical-crosslinking affords a method for the preparation of cellulose aerogels with high mechanical properties [4-6]. Although many efforts have been carried out for the improvement of the mechanical properties of cellulose aerogels, the substances that can provide safe, renewable, and biocompatible nontoxic are more desirable.

Regarding to the chemical nature, chitosan and cellulose have similar structure, with the same $\beta$-glycosidic linkages, being the main difference the presence of primary amino groups at most of the C-2 positions in chitosan, in place of the hydroxyl groups of cellulose. Much work has been devoted to the study of chitosan blends with cellulose [7-10], poly (vinyl alcohol) [11-13], gelatin [14], collagen [15] and others [7]. The evidence of some chitosan-cellulose interactions were found. The chemical reaction of the chitosan amino groups with cellulose carbonyl Groups was proved [3].

In the current work, we firstly reported a reinforced MFC aerogel and its application with the addition of chitosan. The aerogels showed mechanical properties improved. Using the reinforced aerogel as absorbent, 4 kinds of heavy metal ions separation were examined in different conditions. The aerogel will have strong potential in heavy metal ions removal.

\section{Experiments}

MFC and chitosan solution preparation were described in our previous work. MFC dispersion with chitosan mixture at $90 / 10$ (MFC to chitosan weight) was mixed to $0.5 \%$ by adding DI water, by a high-shear mixer for $5 \mathrm{~min}$, followed by a magnetic bar stirring for $1 \mathrm{~h}$, and then sonication for another $30 \mathrm{~min}$. Then the mixture was centrifuged to remove water at a speed of $1.2 \times 10^{4} \mathrm{rpm}$ for $1 \mathrm{~h}$. A gel was formed.

The gel was frozen by liquid nitrogen, then placed on freezer dryer (Labconco) for at least $48 \mathrm{~h}$. The aerogel morphology was monitored in SEM in Figure 1. Pure MFC aerogel has much open structure and very weak bonding strength, see Fig.1 Left; chitosan reinforced MFC aerogel has tight structure and more contacts of fibrils, see Fig.1 right. The properties were examined like density, strength and BET surface area. The aerogel density was measured by the volume and weight of $0.0397 \mathrm{~g} / \mathrm{cm}^{3}$. The strength was evaluated by its water stability which was conducted in water for stirring at given time. The aerogel were soaked into water and kept under magnetic stirring at 610rpm for $4 \mathrm{~h}$, its shape and size were kept intact, while aerogel without chitosan was dispersed into water 
see Fig.2. The interaction between MFC and chitosan in aerogel was examined by FTIR in Figure 3. It is proved that the chitosan spectra disappeared $1650,1560 \mathrm{~cm}-1$, which were assigned to $\mathrm{O}-\mathrm{C}=\mathrm{N}$, implying the chemical reaction between chitosan and cellulose[3]. MFC with chitosan aerogel BET surface area of $9.7 \mathrm{~m}^{2} / \mathrm{g}$ were measured after $4 \mathrm{~h}$ degassing at $105^{\circ} \mathrm{C}$ ( Gemini VII Series Surface Area Analyzer, Micromeritics Instrument Corporation). The separation test was conducted as: $5 \mathrm{mg}$ of dry aerogel in $25 \mathrm{~mL}$ of metal ion solution for some time at $\mathrm{pH} 6$ adjusted with $\mathrm{HNO} 3(0.01 \mathrm{M})$ or $\mathrm{NaOH}(0.01 \mathrm{M})$ using a $\mathrm{pH}$ meter. The mixture was centrifuged and filtered. $10 \mathrm{~mL}$ filtrate was taken to measure the residual ions concentration. 4 kinds of metal ions, $\mathrm{Cr} 6+, \mathrm{Zn} 2+, \mathrm{Cd} 2+$ and $\mathrm{Pb} 2+$, were selected. The Perkin Elmer 8000 ICP-OES was used to analyze the concentration of heavy metal ions. Different contact time and different initial concentration were conducted respectively. All measurements were repeated three times.

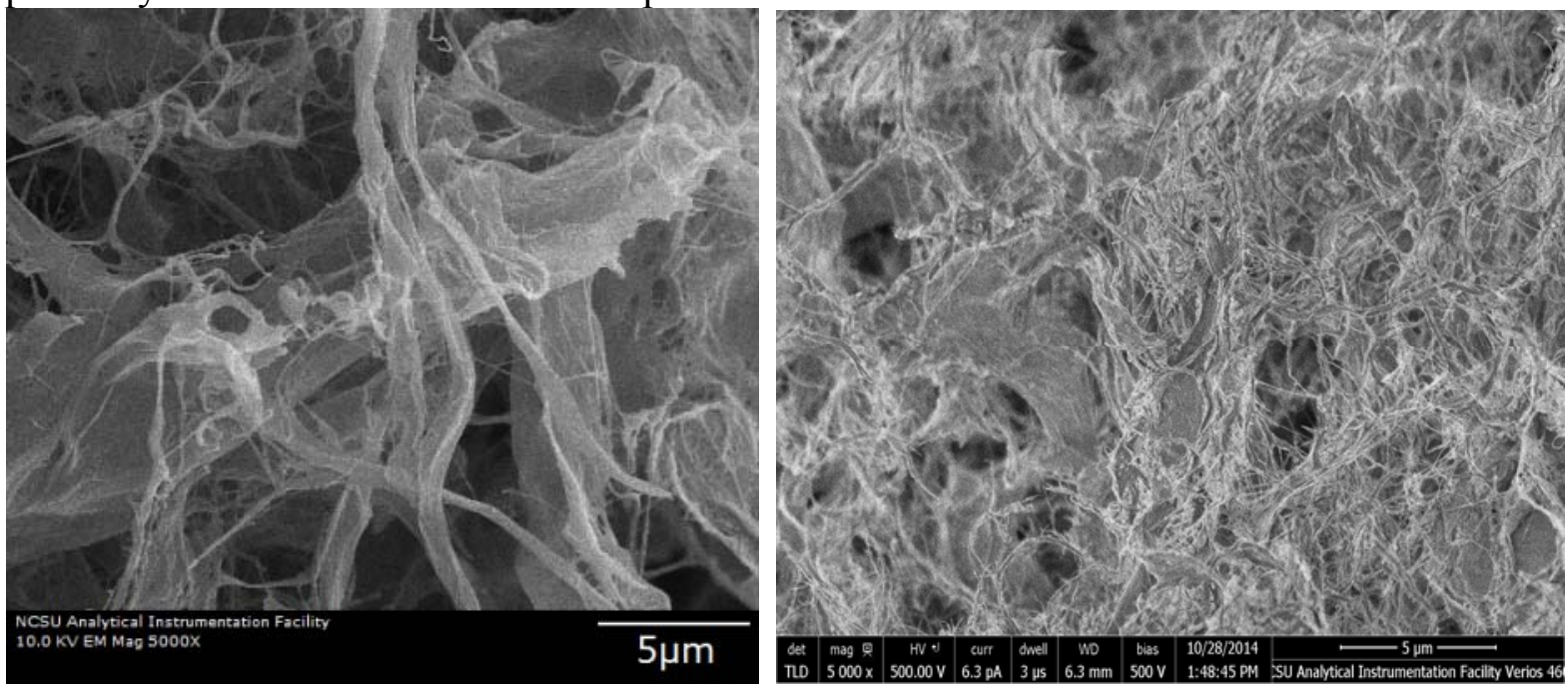

Fig .1 SEM images of MFC aerogel without chitosan (left) and with chitosan (right)
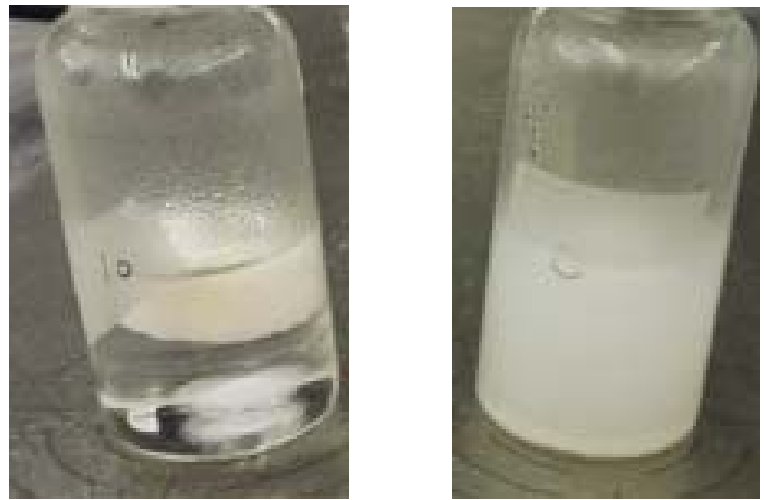

Fig.2 MFC aerogel water stability (left: chitosan reinforced MFC aerogel, right: pure MFC aerogel) 


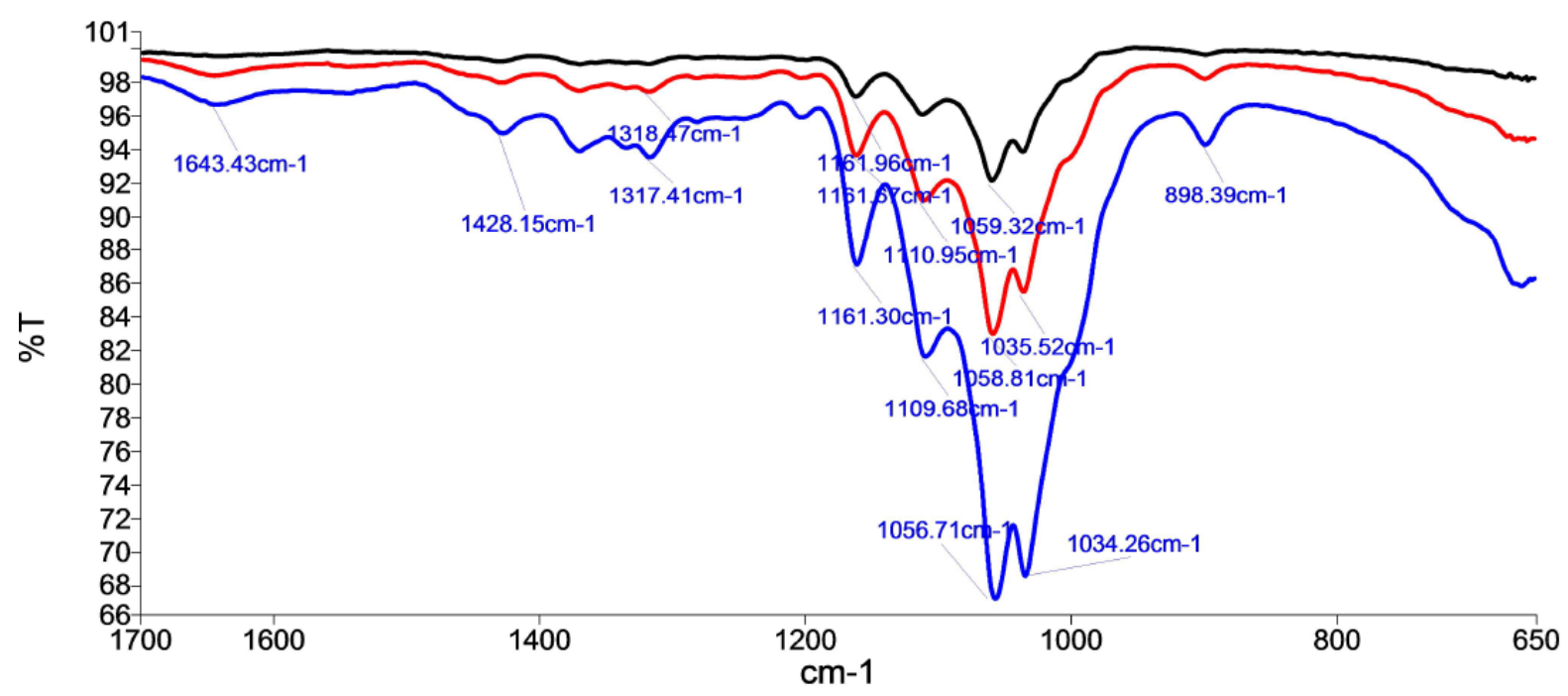

Fig 3 FTIR spectra of MFC aerogel without chitosan (black) and with chitosan $20 \%$ (red) and $30 \%$ (blue)

\section{Results and discussion}

4 kinds of metal ions solution were separated by the reinforced MFC aerogel using 20-120min different contact time range. The initial metal ions concentration are $100 \mathrm{mg} / \mathrm{L}$. After $5 \mathrm{mg}$ aerogel absorbent was applied, the residual metal ions concentration was measured and recorded in Figure 4 . We can see that the contact time has little effect on all metal ions separation since the curves are near flat during 20-120min contact time test range. In other words, the aerogel absorbed the ions very quickly to its absorption equilibrium. Among these 4 ions, $\mathrm{Cd} 2+$ removal rate is close to $100 \%$, the residual ion concentration less than $5 \mathrm{mg} / \mathrm{L} ; \mathrm{Zn} 2+$ was removed the second most to $20 \mathrm{mg} / \mathrm{L}$; Cr6+ and $\mathrm{Pd} 2+$ were removed the least to near 50\%. The aerogel performed as very good absorbent for heavy metal ions both good effectivity (short contact time) and high removal efficiency (high removal rate), typically for $\mathrm{Cd} 2+$ and $\mathrm{Zn} 2+$ here. 4 kinds of ions were ranked $\mathrm{Cd} 2+>\mathrm{Zn} 2+>\mathrm{Pb} 2+\sim \mathrm{Cr} 6+$ by removal rate in Fig. 4 .

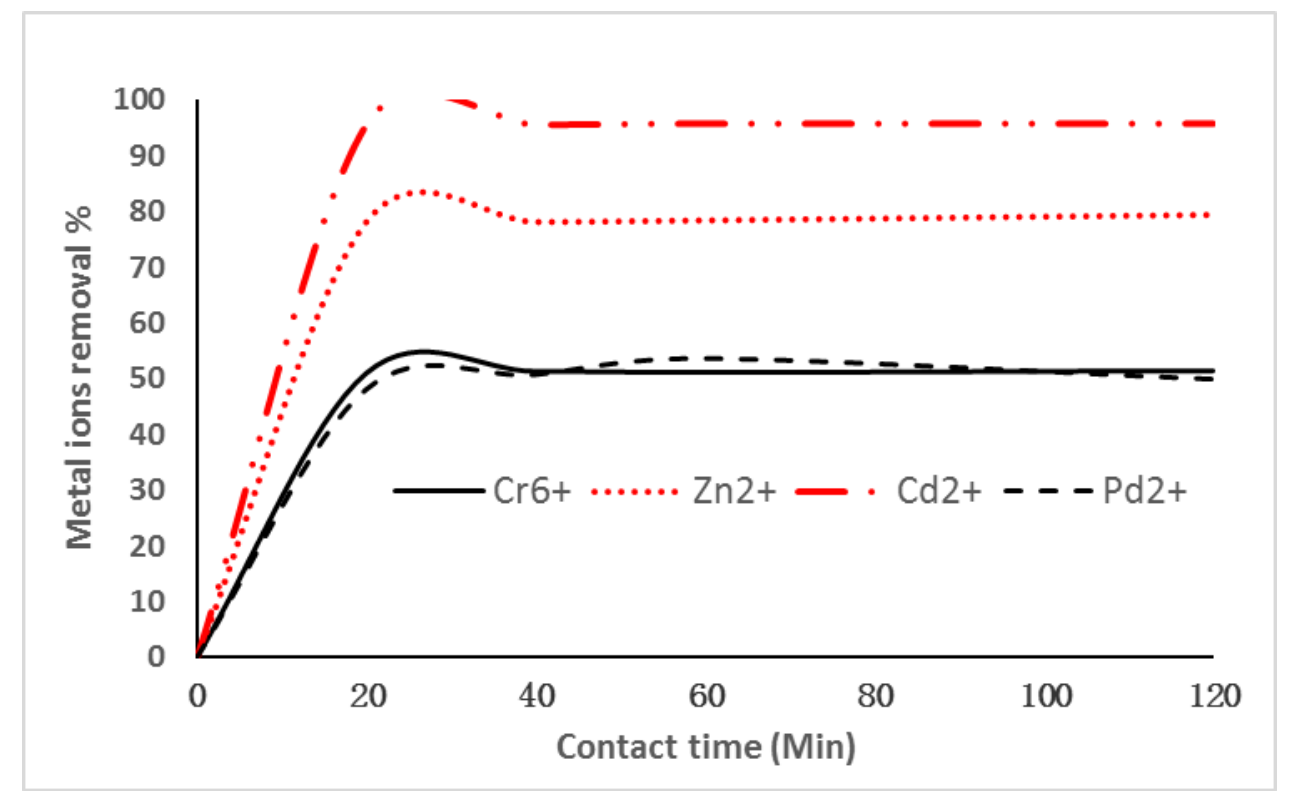

. Fig 4 Effect of contact time on heavy metal ions removal by chitosan reinforced MFC aerogel. 
Figure 5 is different initial metal ions concentration effect on removal percent using $5 \mathrm{mg}$ aerogel and 60min contact time. 4 kinds of ions performed differently. Cr6 + and $\mathrm{Zn} 2+$ ions removal rate had little effect on initial concentrations since their curves are almost flat in Figure 4.But Zn2+ was removed around $80 \%$, much more than $\mathrm{Cr} 6+$, over $50 \%$ removal rate by the aerogel. $\mathrm{Cd} 2+$ and $\mathrm{Pd} 2+$ had better removal rate at lower initial concentration, typically below $100 \mathrm{mg} / \mathrm{L}$ here. At higher initial concentration, both ions removal rate decreased, especially $\mathrm{Cd} 2+.4$ kinds of ions removal rate ranked $\mathrm{Zn} 2+>\mathrm{Cd} 2+\sim \mathrm{Cr} 6+>\mathrm{Pb} 2+$ at higher initial separation concentration in Fig.5.

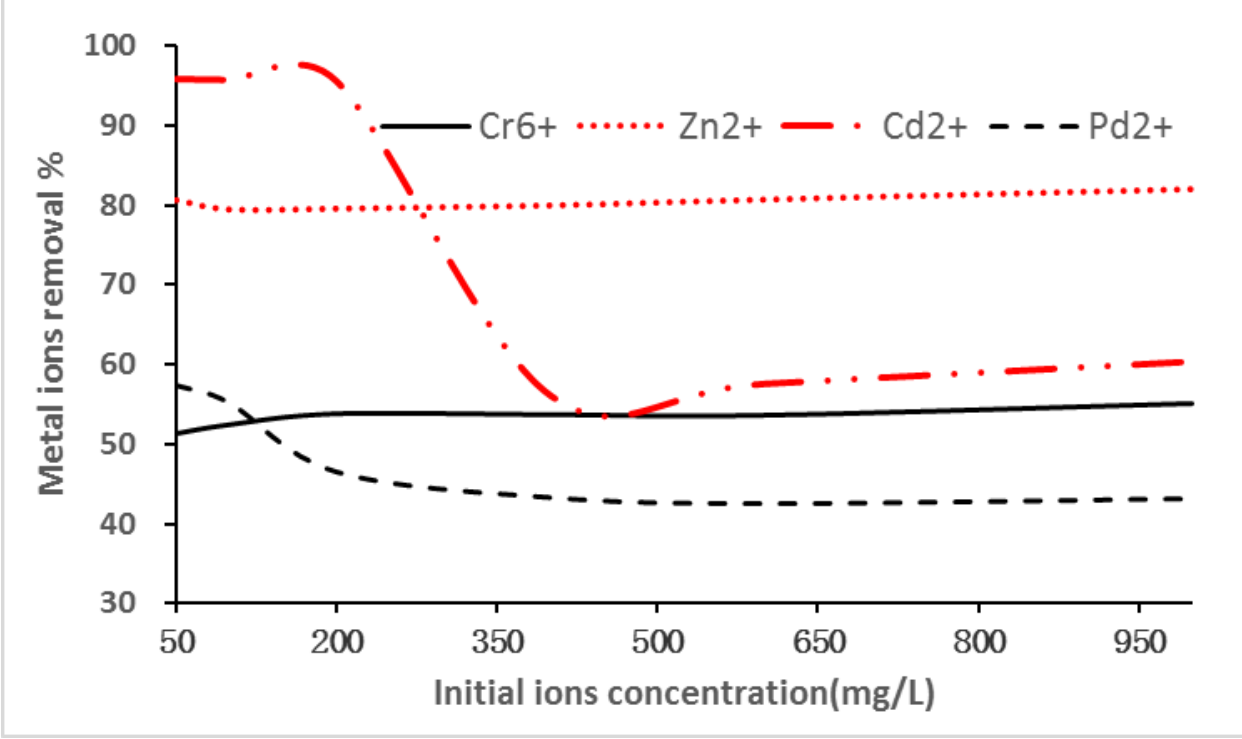

Fig. 5. Effect of initial metal ions concentration on percent removal by chitosan reinforced MFC aerogel

The amount of metal ion adsorbed on the aerogel, qe $(\mathrm{mg} / \mathrm{g})$, was calculated according to eq (1):

$q_{\varepsilon}=\frac{\left(C D-C_{\varepsilon}\right) \psi}{W}$

where $\mathrm{C} 0$ and $\mathrm{Ce}$ are the initial and equilibrium metal ion concentrations $(\mathrm{mg} / \mathrm{L}), \mathrm{V}$ is the volume of the metal ion solution used in the adsorption experiment $(\mathrm{mL})$, and $\mathrm{W}$ is the weight of the aerogel (mg), respectively. Different initial concentration qe was calculated in Table 1.

Tab 1 Experimental qe Values $(\mathrm{mg} / \mathrm{g})$

\begin{tabular}{|l|l|l|l|l|}
\hline $\begin{array}{c}\text { Initial } \\
\text { Con. mg/L }\end{array}$ & \multicolumn{1}{|c|}{$\mathrm{Cd2}+\mathrm{qe}$} & $\mathrm{Zn2}+\mathrm{qe}$ & $\begin{array}{c}\mathrm{Pb} 2+ \\
\text { qe }\end{array}$ & $\begin{array}{c}\mathrm{Cr6}+ \\
\text { qe }\end{array}$ \\
\hline 50 & 474 & 401 & 285 & 247 \\
\hline 100 & 479.5 & 399 & 279 & 267.5 \\
\hline 200 & 475.5 & 392.5 & 227.5 & 259.3 \\
\hline 400 & 277.5 & 397.1 & 213.8 & 263.8 \\
\hline 600 & 284.2 & 401.7 & 210 & 260 \\
\hline 1000 & 297 & 407 & 215.5 & 272.5 \\
\hline
\end{tabular}

*Contact time $60 \mathrm{~min}, \mathrm{pH}=6$

In Tab 1, 4 kinds of ions had very high qe values, much higher than reference [16]. The later using carbon aerogel for absorbent at $1-5 \mathrm{mg} / \mathrm{L}$ initial concentration range, reported $\mathrm{Cd} 2+,(400.8$ $\mathrm{mg} / \mathrm{g}), \mathrm{Zn} 2+(1.84 \mathrm{mg} / \mathrm{g})$, and $\mathrm{Pb} 2+(0.70 \mathrm{mg} / \mathrm{g})$.

\section{Conclusions}

The chitosan reinforced MFC aerogel was prepared successfully. Its micro-structure is much tighter than pure MFC aerogel. The reinforced MFC aerogel has water stability. FTIR proved the chemical bonds between MFC and chitosan groups. The reinforced aerogel was used as heavy metal ions 
absorbent. This aerogel absorbent had good absorption capacity of over $200 \mathrm{mg} / \mathrm{g}$ for all 4 kinds of heavy metal ions, $\mathrm{Cd} 2+, \mathrm{Zn} 2+, \mathrm{Pb} 2+$ and $\mathrm{Cr} 6+$ in the initial concentration range of $50-1000 \mathrm{mg} / \mathrm{L}$. The aerogel had little effect on contact time, but showed dependence on ions initial concentration. The reinforced MFC aerogel is a novel and attractive absorbent for heavy metal ions separation.

\section{Acknowledgement}

In this paper, the research was assisted by Dr. Juliana Da Silva. Prof. Orlando Rojas of North Carolina State University (Raleigh, NC 27695, USA) gave constructive suggestions and support during the whole work. The author are grateful to them.

\section{References}

[1] Eichhorn, S. J., Dufresne, A., Aranguren, M., Marcovich, N. E., Capadona, J. R., Rowan, S. J., et al. (2010). Review: Current international research into cellulose nanofibres and nanocomposites. Journal of Materials Science, 45(1), 1-33.

[2] Moon, R. J., Martini, A., Nairn, J., Simonsen, J., \& Youngblood, J. (2011). Cellulose nanomaterials review: Structure, properties and nanocomposites. Chemical Society Reviews, 40(7), 3941-3994.

[3] J.M. Urreaga, M.U. de la Orden, Chemical interactions and yellowing in chitosan-treated cellulose, European Polymer Journal, Volume 42, 2006, 2606-2616

[4] W.Zhang, Y. Zhang, C. Lu, Y. Deng, Aerogels from crosslinked cellulose nano/micro-fibrils and their fast shape recovery property in water, J. Mater.Chem. 2012, 22,11642-11650

[5] M.D. Gawryla, D.A. Schiraldi, Novel absorbent materials created via ice templating,

Macromol. Mater. Eng. 294 (2009) 570-574.

[6] S. Liu, T. Yu, N. Hu, R. Liu, X. Liu, High strength cellulose aerogels prepared by spatially confined synthesis of silica in bioscaffolds, Colloids and Surfaces A: Physicochem. Eng. Aspects 439 (2013) 159- 166.

[7] Twu YK, Huang HI, Chang SY, Wang SL. Carbohydr Polym 2003;54:425-30.

[8] Hasegawa M, Isogai A, Onabe F, Usuda M, Atalla RH. J Appl Polym Sci 1992;45:1873-9.

[9] Rogovina SZ, Akopova TA, Vikhoreva GA, Gorbacheva IN. Polym Deg Stab 2001;73:557-60.

[10] Wu YB, Yu SH, Mi FL, Wu CW, Shyu SS, Peng CK, et al. Carbohydr Polym 2004;57:435-40.

[11] Yang JM, Su WY, Leu TL, Yang MC. J Membrane Sci 2004;236:39-51.

[12] Cho YW, Han SS, Ko SW. Polymer 2000;41:2033-9.

[13] Paradossi G, Lisi R, Paci M, Crescenzi V. J Polym Sci Part A: Polym Chem 1996;34:3417-25.

[14] Arvanitoyannis IS, Nakayama A, Aiba S. Carbohydr Polym 1998;37:371-82.

[15] Sionkowska A, Wisniewski M, Skopinska J, Kennedy CJ, Wess TJ. Biomaterials 2004;25:795-801.

[16] Ajay Kumar Meena, G.K. Mishra, P.K. Rai, Chitra Rajagopal, P.N. Nagar, Removal of heavy metal ions from aqueous solutions using carbon aerogel as an adsorbent, Journal of Hazardous Materials B122 (2005) 161-170. 